\title{
Variational Analysis of Simulated Ocean Surface Winds from the Cyclone Global Navigation Satellite System (CYGNSS) and Evaluation Using a Regional OSSE
}

\author{
S. MARK LEIDNER \\ Atmospheric and Environmental Research, Inc., Lexington, Massachusetts \\ BACHIR ANNANE \\ NOAA/Atlantic Oceanographic and Meteorological Laboratory, and Cooperative Institute for Marine \\ and Atmospheric Studies, University of Miami, Miami, Florida \\ BRIAN MCNOLDY \\ Rosenstiel School of Marine and Atmospheric Science, University of Miami, Miami, Florida \\ ROSS HOFFMAN \\ NOAA/Atlantic Oceanographic and Meteorological Laboratory, and Cooperative Institute for Marine \\ and Atmospheric Studies, University of Miami, Miami, Florida \\ ROBERT ATLAS \\ NOAA/Atlantic Oceanographic and Meteorological Laboratory, Miami, Florida
}

(Manuscript received 16 August 2017, in final form 9 May 2018)

\begin{abstract}
A positive impact of adding directional information to observations from the Cyclone Global Navigation Satellite System (CYNGSS) constellation of microsatellites is observed in simulation using a high-resolution nature run of an Atlantic hurricane for a 4-day period. Directional information is added using a twodimensional variational analysis method (VAM) for near-surface vector winds that blends simulated CYGNSS wind speeds with an a priori background vector wind field at 6-h analysis times. The resulting wind vectors at CYGNSS data locations are more geophysically self-consistent when using high-resolution 6-h forecast backgrounds from a Hurricane Weather Research and Forecast Model (HWRF) control observing system simulation experiment (OSSE) compared to low-resolution 6-h forecasts from an associated Global Forecast System (GFS) model control OSSE. An important contributing factor is the large displacement error in the center of circulation in the GFS background wind fields that produces asymmetric circulations in the associated VAM analyses. Results of a limited OSSE indicate that CYGNSS winds reduce forecast error in hurricane intensity in 0-48-h forecasts compared to using no CYGNSS data. Assimilation of VAM-CYGNSS vector winds reduces maximum wind speed error by $2-5 \mathrm{kt}\left(1 \mathrm{kt}=0.51 \mathrm{~m} \mathrm{~s}^{-1}\right)$ and reduces minimum central pressure error by $2-5 \mathrm{hPa}$. The improvement in forecast intensity is notably larger and more consistent than the reduction in track error. The assimilation of VAM-CYGNSS wind vectors constrains analyses of surface wind field structures during OSSE more effectively than wind speeds alone. Because of incomplete sampling and the limitations of the data assimilation system used, CYGNSS scalar winds produce unwanted wind/ pressure imbalances and asymmetries more often than the assimilation of VAM-CYGNSS data.
\end{abstract}

\section{Introduction}

The NASA Cyclone Global Navigation Satellite System (CYNGSS) mission provides new and improved

Corresponding author: S. Mark Leidner, mleidner@aer.com observations of ocean surface winds in the tropics (Ruf et al. 2016). The CYGNSS constellation of eight microsatellites was launched on 15 December 2016 from Kennedy Space Center in Florida. This paper documents prelaunch research to test and assess the potential impact of CYGNSS observations on the analysis and 
forecasts of hurricanes. Also, this extends the study of McNoldy et al. (2017) by testing the impact of varying data assimilation cycling frequency and using a variational method to estimate wind direction.

The measurement of ocean surface winds within a $100-\mathrm{km}$ radius of the center of tropical cyclones has long been difficult. In situ shipboard measurements are dangerous, threatening life and property. In situ buoy measurements of wind speed within tropical cyclones are often affected by the highly disturbed sea state (large vertical movement from high swell, blowing sea foam, wind shadowing by high swell, etc.) and are not reliable observations of winds under such extreme conditions. When heavy rain from intense bands of convection is present, as is often the case near the centers of tropical cyclones, passive and active microwave remote sensing of ocean surface winds from space can be dominated by emissions or reflections from hydrometeors, and the microwave signature of the ocean surface (related to wind speed) is compromised (e.g., for C-band scatterometers) or lost altogether (e.g., for most microwave radiometers). The stronger a tropical cyclone becomes and the more widespread intense convection, the more the integrity of all these ocean surface wind measurement techniques is substantially reduced.

CYGNSS measures the pattern and intensity of global positioning system (GPS) signals scattered and reflected by the ocean surface centered at specular reflection points. The received signal is related to ocean surface roughness and is therefore a proxy for wind speed. The dual-frequency GPS carrier signals at 1575.42 and $1227.60 \mathrm{MHz}$ are in a "window" region of the electromagnetic spectrum with respect to propagation through Earth's atmosphere and are essentially unaffected by the presence of hydrometeors. The GPS signals are refracted by Earth's atmosphere, but they are otherwise unaffected. This gives CYGNSS the opportunity to retrieve winds at the ocean surface, very near the center of tropical cyclones, with a temporal frequency and accuracy previously impossible in practice.

CYGNSS ocean surface wind speed is retrieved along each track of specular reflecting points at an interval of approximately $5 \mathrm{~s}$ and $25 \mathrm{~km}$. Note that up to four specular points may be tracked simultaneously by each of the eight CYGNSS spacecraft. In this paper we use a variational analysis method (VAM) that adds information to retrieved CYGNSS scalar wind speeds to estimate what we will term VAM-CYGNSS wind vectors. Vector winds implicitly provide low-level convergence/ divergence and vorticity information to atmospheric data assimilation (DA) systems that scalar winds alone cannot provide. Information about patterns of nearsurface convergence and vorticity from VAM-CYGNSS wind vectors could prove vital in advanced DA systems that can propagate surface wind information vertically and to other variables in the lower troposphere. Many tropical cyclones exhibit strongly nonlinear strengthening and weakening during their lifetimes, and reliable forecasts of hurricane intensity remain a difficult scientific challenge (Gall et al. 2013). Thus, it is critically important to provide accurate and detailed analyses of hurricanes as the initial conditions for weather forecast models.

The sections that follow progress roughly in the order required to conduct this study. Section 2 describes how the simulated CYGNSS observations were created. Section 3 describes the VAM analysis technique and its application to the research questions being addressed. Section 4 describes the sources for an essential input to the VAM: the background or a priori gridded vector winds. Section 5 presents results from the VAM wind vector analyses, and section 6 illustrates the impacts of different analysis approaches on hurricane analyses and forecasts in an observing system simulation experiment (OSSE). Note that the Weather Research and Forecasting (WRF) Model generates the high-resolution nature run used to simulate the CYGNSS observations and that the Hurricane Weather Research and Forecasting Model (HWRF) is used in all DA and forecast experiments. These models have two different dynamical cores.

\section{Simulated CYGNSS wind speed observations}

CYGNSS wind speed observations were simulated using the end-to-end simulator (E2ES), developed by NASA's CYGNSS Science Team (O'Brien 2014). The E2ES is driven by input wind field information from high-resolution weather forecast models, corresponding sea surface information, and the geometry of the path taken by the reflected GPS signals from the ocean surface. The E2ES produces either delay Doppler maps (DDMs; Level 1 product) or retrieved winds (Level 2 product) using a "fast forward model" option. To simulate DDMs every second along a specular point track, the standard forward model integrates 1000 consecutive 1-ms power outputs of the reflected GPS signal, consistent with the CYGNSS onboard delay Doppler mapping instrument (DDMI). To economize processing time, the fast forward model option integrates only 100 consecutive 1-ms power outputs (i.e., every $10 \mathrm{~ms}$ ) to estimate DDMs used to generate retrieved winds every second along a specular point track. For further details on coherent and noncoherent integration of reflected GPS signals, see Gleason et al. (2005). In this study the hurricane nature run of Nolan et al. (2013; HNR1) was used 
as the input wind field information to simulate CYGNSS retrieved winds. Given the modeled orbital ephemeris of both the CYGNSS and GPS constellations, the E2ES samples patches of the sea surface from the HNR1 inputs in the vicinity of specular reflection points as would be observed by CYGNSS to create DDMs. HNR1 winds and sea surface characteristics closest in space and time fill patches around each local specular reflection point to facilitate the forward model calculation of DDMs. The simulated DDMs are then inputs to a wind speed retrieval algorithm (Clarizia and Zavorotny 2015) to determine estimates of the local wind speed. While DDMs typically measure reflected GPS signals over a relatively large glistening zone, about $100-150 \mathrm{~km}$ in radius around the specular point, with generally low reflected power, the CYGNSS wind speed retrieval uses only the portion of each simulated DDM that is within $12-15 \mathrm{~km}$ of the specular point, the region with the highest reflected GPS signal power. Simulated CYGNSS data were generated for a 4-day period (0000 UTC 1-5 August 2005) of the HNR1 when the simulated hurricane forms in the western tropical North Atlantic and moves north-northwestward as it undergoes rapid intensification during the $24 \mathrm{~h}$ centered on 1200 UTC 3 August 2005.

The HNR1 simulates a highly realistic hurricane using the WRF with three nested hurricane-following grids of 9,3 , and $1 \mathrm{~km}$ inside a fixed outer $27-\mathrm{km}$ grid domain. HNR1 is driven by initial and lateral boundary conditions from the ECMWF 26-km resolution ${ }^{1}$ T511 Joint OSSE nature run (JONR; Reale et al. 2007; Masutani et al. 2009). To maintain a close correspondence between the tropical cyclone (TC) track in both the JONR and the HNR1, Nolan et al. (2013) nudge (see Stauffer and Seaman 1990) the HNR1 27-km domain grid points toward the JONR. HNR1 fields are available every 30 min throughout the simulation, and the E2ES selects grids closest in time to the current specular point. The highest grid resolution available is used by the E2ES, depending on the location of each specular point within the HNR1 nested grids at that time. Because the inner three WRF grids move with the hurricane during the simulation, specular points near or coincident with the eyewall of the hurricane fall within the $1-\mathrm{km}$ grid. Wind field and sea surface information at locations farther from the center of the hurricane are supplied by HNR1 grids at lower resolutions, but these are naturally locations where fine resolution is not required.

\footnotetext{
${ }^{1}$ For consistency, the L1 resolution of Laprise (1992) is used throughout this paper, although ECMWF typically reports the L2 resolution, which is $39 \mathrm{~km}$ for T511.
}

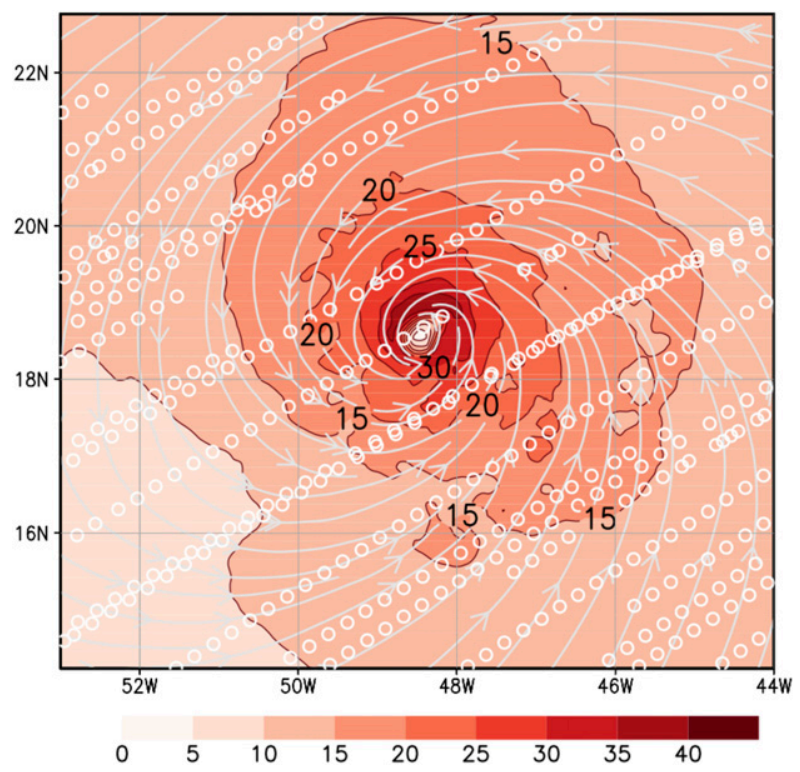

FIG. 1. Nature run (HNR1) 10-m wind speed from the 9-km domain, valid at 1200 UTC 3 Aug 2005. Wind stream lines are overlaid (gray), as are locations of simulated CYGNSS wind speed observations (open white circles). Every fifth simulated CYGNSS observation location is plotted for clarity. Simulated CYGNSS wind speed observations are valid in a 6 -h window, $\pm 3 \mathrm{~h}$ around 1200 UTC.

Observations created directly from the HNR1 wind fields are considered "perfect"; that is, they do not include observation error. However, the CYGNSS Science Team also produced simulated wind speed observations using the fast forward model option within the E2ES that include realistic estimated wind speed errors. There are two sources of E2ES wind speed error: 1) uncertainties in the calibration of the DDMs and 2) uncertainties in the retrieved wind speed, assuming the DDMs are perfectly calibrated (A. O'Brien 2016, personal communication). The DDM calibration uncertainty model is a parametric fit of simulated DDM calibration/validation data to a generalized Gaussian distribution, while the wind speed retrieval error model is a random draw from a normal Gaussian distribution with zero mean and standard deviation of $1.2 \mathrm{~m} \mathrm{~s}^{-1}$. These two terms are computed and added to each perfect wind speed observation to create simulated winds with realistic observation error characteristics. Since the simulated observations contain no gross error, no special quality control procedures were used.

Figure 1 shows the HNR1 wind field $10 \mathrm{~m}$ above the ocean surface, valid at 1200 UTC 3 August. The hurricane in Fig. 1 is a well-developed category 2 hurricane with a maximum wind speed of $40.0 \mathrm{~m} \mathrm{~s}^{-1}$. It is still undergoing rapid intensification and $12 \mathrm{~h}$ later at 
0000 UTC 4 August, peak winds briefly top $60 \mathrm{~m} \mathrm{~s}^{-1}$. Figure 1 also shows locations of the simulated CYGNSS winds speeds from the E2ES, sampled from HNR1, with realistic observation errors added for observations within a 6-h window centered on 1200 UTC 3 August. The maximum simulated CYGNSS wind speed is $42.8 \mathrm{~m} \mathrm{~s}^{-1}$ (not shown). Because the winds are sampled from the nearest 30-min outputs from HNR1, the nearest HNR1 time to the simulated CYGNSS observations of the hurricane center over the 6-h observation window of 0900-1500 UTC is the 1500 UTC time with an HNR1 maximum wind speed of $43.5 \mathrm{~m} \mathrm{~s}^{-1}$. For this time period with excellent coverage of the hurricane circulation by the CYGNSS constellation, the simulated CYGNSS observations produced by the E2ES captures the maximum wind speed very well.

\section{Variational analysis method}

The central aim of this study is to create CYGNSS winds with added directional information and to assess the quality and potential impacts of these derived VAM-CYGNSS vector winds. Conversion of simulated scalar CYGNSS wind observations (cf. section 2) to vector winds requires some a priori or background estimate of the vector wind field to be combined with the wind speed retrieval at each CYGNSS specular point. The choice of vector wind backgrounds is described in section 4.

Rather than using a nearest-neighbor or other approach to assign wind direction given the background wind field information, a VAM is used that combines simulated CYGNSS wind speed observations with vector background wind fields to find an optimal vector wind field solution. The optimal wind solution is then interpolated to the CYGNSS observation locations to derive wind vector observations. The VAM was developed by Hoffman $(1982,1984)$ to combine retrieved scatterometer winds with a background wind field. Hoffman et al. (2003) applied this approach to choose a unique scatterometer vector wind from among a set of two to four of the most likely retrieved wind vectors. The VAM has been used to generate long-period highresolution global ocean surface wind vector datasets (Atlas et al. 2011). These datasets have been used by the scientific community for more than 20 years with the original version based solely on wind speeds from the Special Sensor Microwave Imager (SSM/I) series (Atlas et al. 1996).

The VAM finds an optimal gridded $u$ and $v$ wind field that is a smoothing spline that simultaneously minimizes 1) the misfit to the background wind field $J_{b}$ and 2) the misfit to the wind speed observations $J_{o}$. The effective background error correlation structure is revealed by single ship wind observation solutions to be a cyclonicanticyclonic dipole with a Gaussian hill amplitude centered on and aligned with the observation (cf. Fig. 2 from Hoffman et al. 2003). An iterative conjugate gradient solver is used to find the minimum. The method is described in detail by Hoffman et al. (2003). ${ }^{2}$ The setup of the VAM used here is the same as used by Atlas et al. (2011). At the start of the iterative analysis process, $J_{b}$ is identically zero (i.e., the background is the current solution), and $J_{o}$, which is proportional to the squared error between the observations and the background, is typically large. During the minimization $J_{b}$ increases as the analysis is modified to be in better agreement with the observations and $J_{o}$ is typically reduced by about an order of magnitude. After many iterations, a minimum of the sum of $J_{b}$ and $J_{o}$ terms satisfies a convergence criterion (i.e., small change compared to the previous iteration). The final solution has been reached and the result is saved.

The VAM was designed to be run at any horizontal resolution, given a regular latitude by longitude grid. For the sake of efficiency, VAM analyses can be generated using multiple resolutions for the same set of observations. For example, a coarse preliminary analysis on a $1^{\circ}$ latitude $\times 1^{\circ}$ longitude grid can serve as a starting point for a subsequent moderate resolution analysis $\left(0.5^{\circ} \times 0.5^{\circ}\right)$. Then the moderate resolution analysis can serve as a starting point for a higher-resolution analysis $\left(0.25^{\circ} \times 0.25^{\circ}\right)$. This progressive grid refinement approach economizes computer time, memory, and the number of minimization iterations to arrive at the same optimal solution compared to a single analysis at high resolution (Hoffman et al. 2003).

\section{Background vector wind fields}

Two sources for $10-\mathrm{m}$ background surface vector winds were used for this study: 1) 6-h forecasts from a Global Forecast System (GFS) global control OSSE (Casey et al. 2016) that used the 2005 operational T382 3D-Hybrid DA system (approximately $35-\mathrm{km}$ resolution), and 2) 6-h forecasts from an HWRF control OSSE (McNoldy et al. 2017; 9-km regional resolution). The GFS model is described by NWS (2014) and the GFS DA system by NOAA (2015). Because this study uses simulated observations, the VAM backgrounds come from related OSSEs. For both the GFS and HWRF OSSE control experiments, conventional, aircraft, and

\footnotetext{
${ }^{2}$ The VAM computer code is available upon request from the corresponding author.
} 

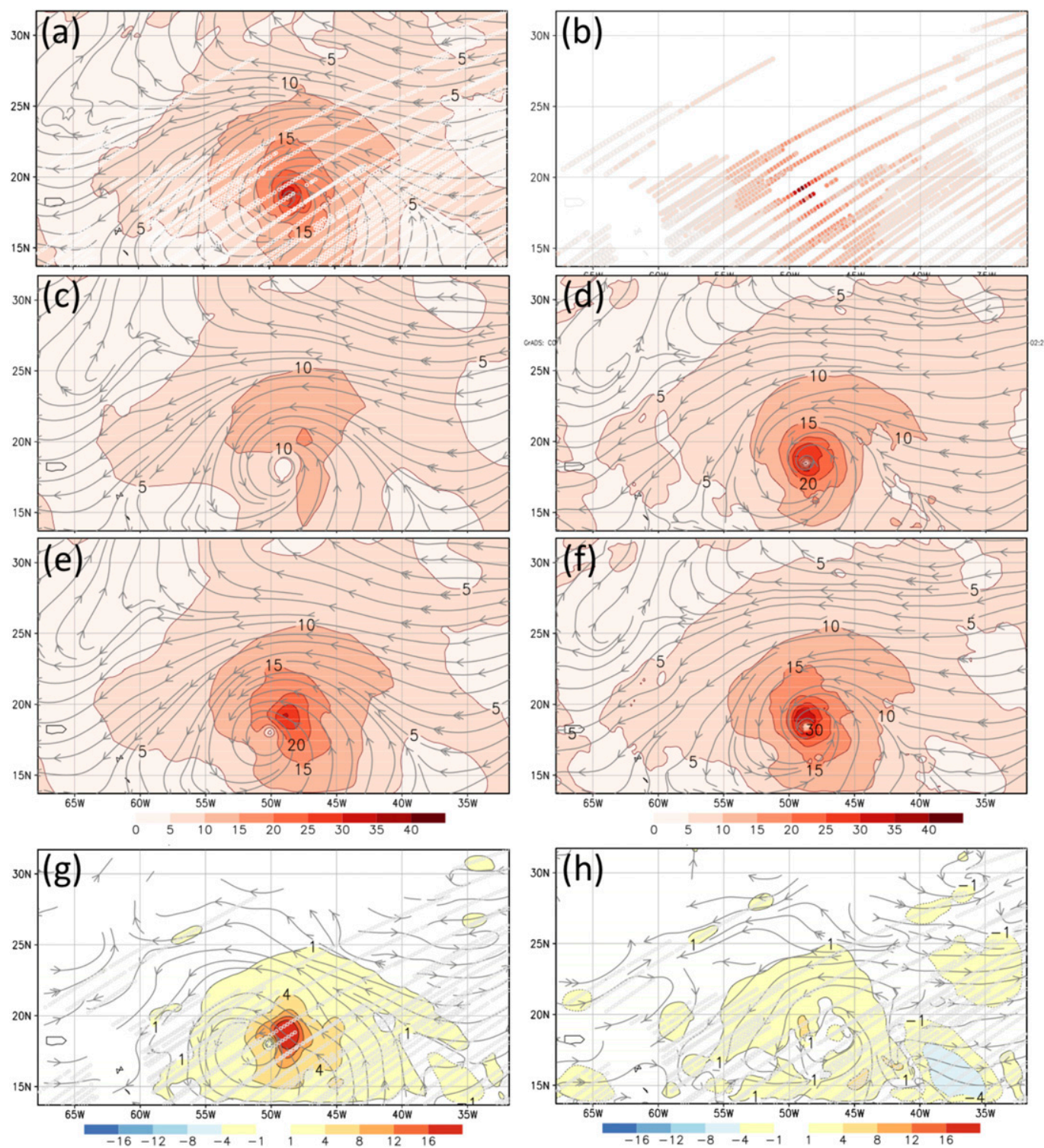

FIG. 2. Nature run (HNR1) winds and VAM analysis results, valid at 1200 UTC 3 Aug 2005 on the VAM $0.25^{\circ}$ grid. (a) HNR1 10-m winds and (b) simulated CYGNSS winds in the \pm 3 -h window around 1200 UTC. (c) GFS and (d) HWRF 6-h forecast backgrounds. (e) $\operatorname{VAM}(\mathrm{G})$ and (f) $\operatorname{VAM}(\mathrm{H})$ analyses. VAM analysis increments for $(\mathrm{g}) \operatorname{VAM}(\mathrm{G})$ and $(\mathrm{h}) \operatorname{VAM}(\mathrm{H})$ analyses. CYGNSS data locations plotted with small gray open circles in $(\mathrm{g})$ and $(\mathrm{h})$.

satellite observations used in NCEP operations as of 2012 and simulated from the JONR are assimilated over the period of the HNR1.

The horizontal resolution of the 6-h forecasts from the GFS global control and the HWRF regional control OSSEs resolves different scales of motion. Also, the GFS global forecast model and the HWRF used to generate these backgrounds are designed and configured quite differently from one another. For example, because of the differences in scales and domains, the GFS and HWRF models employ different parameterizations of convection, boundary layer processes, surface fluxes, and other physical processes. Therefore, the VAM results using these backgrounds can be viewed differently. VAM results using the GFS global control OSSE forecast winds for the background [VAM $(\mathrm{G})$ results] can be viewed as a baseline CYGNSS result, that is, the result of using readily available global forecast model fields. Whereas VAM results using mesoscale HWRF control OSSE forecast winds for the backgrounds $[\operatorname{VAM}(\mathrm{H})$ results] reflect results that are closer to what may be obtained operationally. 


\section{Variational analysis results}

The VAM analysis domain for this study, shown in Figs. 2 and 3 , is a portion of the western tropical North Atlantic, $36^{\circ}$ longitude $\times 18^{\circ}$ latitude in extent, and does not change over the 4-day period. Analyses are generated every $6 \mathrm{~h}$ at synoptic times $(0000,0600,1200$, and 1800 UTC) for the period 1200 UTC 1 August0000 UTC 5 August. At each analysis time, the VAM ingests all simulated CYGNSS wind speeds in a 6-h window centered on the synoptic time and three background wind fields, valid at the analysis time and $6 \mathrm{~h}$ before and after the analysis time. Three time levels of the background winds are needed to use the first guess at the appropriate time (FGAT) option in the VAM that produces time-interpolated background estimates at individual observation times (Atlas et al. 2011). As described in section 3, each VAM analysis is the result of a multiscale analysis procedure that telescopes from a $1^{\circ}$ to a $0.5^{\circ}$ to a final $0.25^{\circ}$-resolution latitude by longitude grid. Initially, the background (GFS or HWRF) $10-\mathrm{m}$ wind components are interpolated linearly to the $1^{\circ}$ VAM grid. At each refinement the background is interpolated linearly again to the $0.5^{\circ}$ or $0.25^{\circ} \mathrm{VAM}$ grid as is the current VAM analysis. Finally, the $0.25^{\circ} \mathrm{VAM}$ analysis is interpolated linearly to the CYGNSS locations to produce VAM wind vectors.

Owing to the sampling characteristics of CYGNSS during this 4-day period, there are no CYGNSS observations within the VAM analysis domain in the 6-h observation windows around 0600 UTC each day. Also, the simulated CYGNSS data \pm 3 h of the 1800 UTC synoptic time do not sample the simulated hurricane or its environment but sample regions in the Atlantic Ocean north of the hurricane. The 0000 and 1200 UTC synoptic times contain the CYGNSS samples near and within the simulated hurricane during this 4-day period.

VAM analyses valid at 1200 UTC 3 August are used next to illustrate the impacts of the background fields on the creation of vector winds from CYGNSS wind speed observations. Figure 2a is similar to Fig. 1, but it shows the HNR1 27-km domain wind field and locations of simulated CYGNSS observations over the VAM analysis region. The wind speed maximum for the $27-\mathrm{km}$ domain is $33.0 \mathrm{~m} \mathrm{~s}^{-1}$. Figure $2 \mathrm{~b}$ shows the CYGNSS wind speed observations over the region for the 6-h observation window centered on 1200 UTC 3 August. The area with no CYGNSS observations in the lowerleft corner of Fig. $2 b$ is due to the presence of landPuerto Rico and the Lesser Antilles.

VAM backgrounds, analyses, and increments for the $\operatorname{VAM}(\mathrm{G})$ and $\operatorname{VAM}(\mathrm{H})$ results are shown in Figs. 2c-2h. Notice that the GFS 6-h forecast background (Fig. 2c; (a)

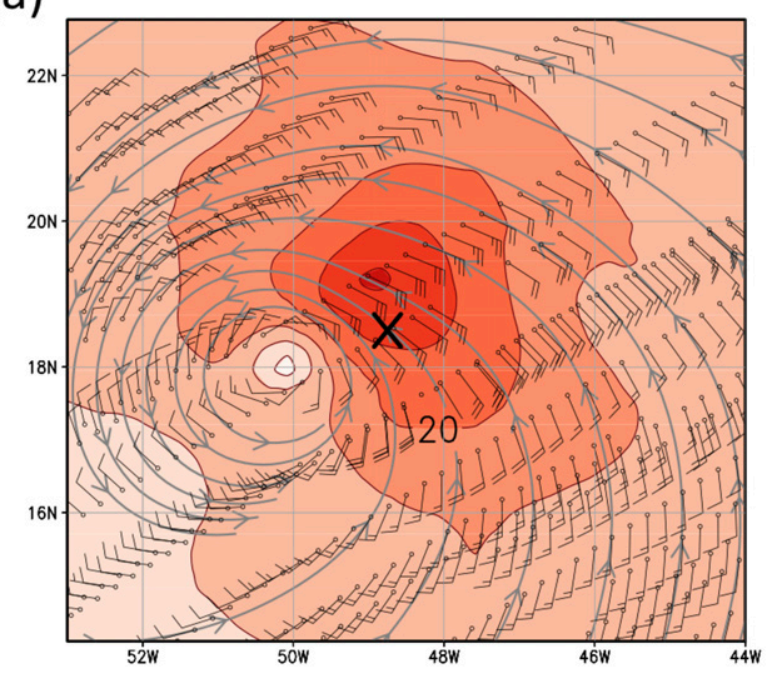

(b)

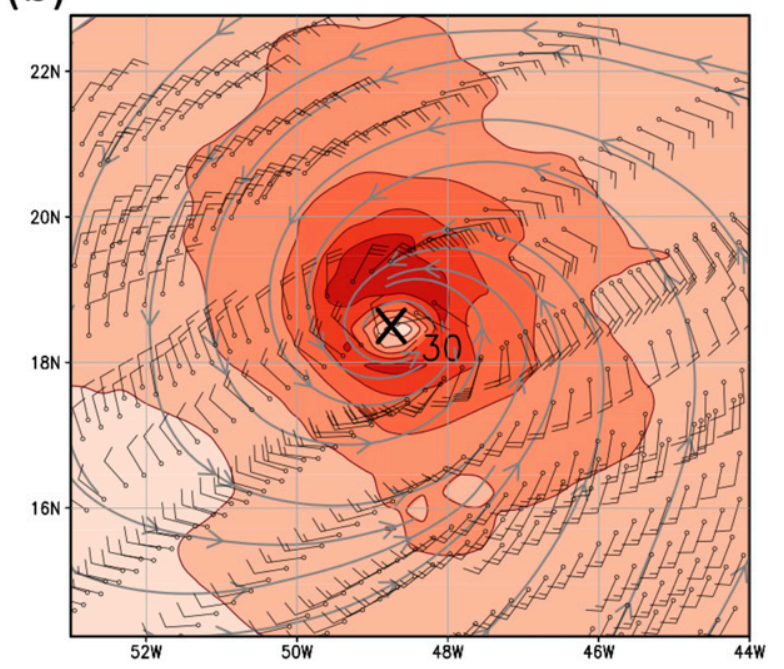

FIG. 3. 10-m wind speed and streamlines from (a) $\operatorname{VAM}(\mathrm{G})$ analysis and (b) the VAM(H) analysis, valid at 1200 UTC 3 Aug on the VAM $0.25^{\circ}$ grid. Derived VAM-CYGNSS observations are overplotted as wind barbs $\left(\mathrm{m} \mathrm{s}^{-1}\right.$; every fifth location as in previous plots). The location of the center of circulation from the nature run (HNR1) is plotted as a bold $\mathrm{X}$ in both panels for reference.

maximum wind speed is $16.5 \mathrm{~m} \mathrm{~s}^{-1}$ ) has a much weaker circulation than the HWRF 6-h forecast background (Fig. 2d; maximum wind speed is $30.7 \mathrm{~m} \mathrm{~s}^{-1}$ ). Also, the location of the circulation center in the GFS background is displaced considerably to the south and west of the HNR1 position (Fig. 2a), whereas the HWRF background is much closer to the HNR1 position. As background winds for these VAM analyses, HWRF 6-h forecasts present a much more realistic hurricane as a starting point. 
(a)

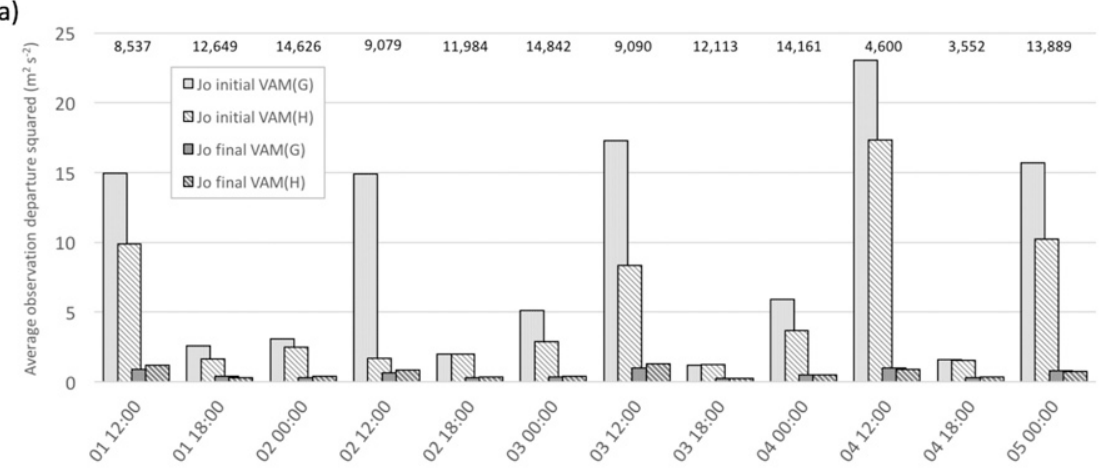

(b)

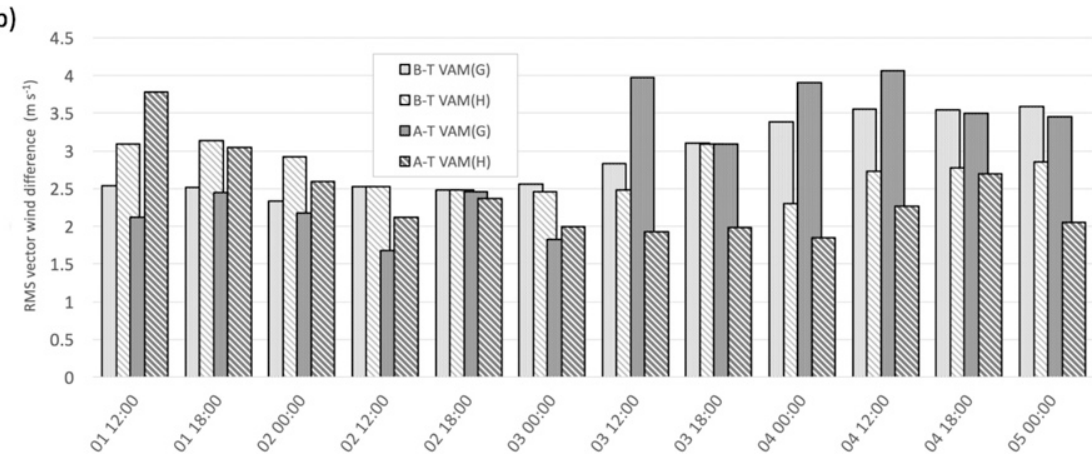

FIG. 4. Time series of (a) the mean squared observation minus background $(o-b)$ and observation minus analysis $(o-a)$ for $\operatorname{VAM}(\mathrm{G})$ and $\operatorname{VAM}(\mathrm{H})$ analyses, and $(\mathrm{b})$ the RMS vector difference of gridded VAM background minus HNR1 "truth" winds $(B-T)$ and VAM analysis winds minus the HNR1 winds $(A-T)$. In (a) the observations are the CYGNSS wind speeds and in (b) the rmsd is over the 10553 points from the HNR1 27-km resolution grid contained in the VAM domain. Values are normalized by the number of observations in each analysis (plotted above each group of bars).

The VAM analyses in Figs. 2e and 2f show hurricane circulations that are markedly different in position and structure. The wind maxima in the $\operatorname{VAM}(\mathrm{G})$ analysis and $\operatorname{VAM}(\mathrm{H})$ analysis are similar, 30.5 and $33.1 \mathrm{~m} \mathrm{~s}^{-1}$, respectively. Both analyzed wind maxima are reduced from the maximum simulated CYGNSS wind speed of $42.8 \mathrm{~m} \mathrm{~s}^{-1}$. This reflects the smoothing properties of the VAM required to satisfy its background and dynamical constraints. But the difference in the structure and location of the hurricane between the two analyses is striking. Because of the significant position error in the GFS background, the resulting $\operatorname{VAM}(\mathrm{G})$ analysis wind field is highly asymmetric and is not a good representation of the wind field in the HNR1 at this time. The VAM analysis increments in Figs. $2 \mathrm{~g}$ and $2 \mathrm{~h}$ show that very large wind speed increments are required in the $\operatorname{VAM}(\mathrm{G})$ analysis to fit the CYGNSS observations well, whereas the $\operatorname{VAM}(\mathrm{H})$ analysis, starting from a better quality background, requires only modest wind increments to achieve a good fit to the CYGNSS observations.
A closer look at the VAM analysis wind fields compared to the nature run wind field is presented in Fig. 3. The displacement of the VAM $(\mathrm{G})$ analysis compared to the nature run position is clear, and the effects of this displacement on the resulting VAM-CYGNSS winds is also clear by comparing the wind barbs in Figs. 3a and 3b. An atmospheric DA system would clearly respond very differently to VAM-CYGNSS wind vector observations derived from the $\operatorname{VAM}(\mathrm{G})$ and $\operatorname{VAM}(\mathrm{H})$ analyses.

Over the 4-day period of the nature run, VAM analyses were generated when CYGNSS data were available within the analysis region. Figure 4 a presents a time series of the observation terms, $J_{o}$ initial and final, from each VAM analysis for both $\operatorname{VAM}(\mathrm{G})$ and $\operatorname{VAM}(\mathrm{H})$ results. The term $J_{o}$ is the sum over all CYGNSS observations of the squared difference between each observation and the background or current analysis value. In Fig. 4a these have been normalized by the number of simulated CYGNSS observations in each cycle, so the bars in the figure are an average of squared departures. 
Notice that the average $J_{o}$ term is largest at the 1200 UTC analysis time, when the simulated CYGNSS sampling of the hurricane is the most complete. The higher simulated CYGNSS wind speed observations within and in the immediate vicinity of the hurricane in the 6-h window around 1200 UTC contribute to large initial $J_{o}$ values. Notice that the analysis departures from observations, final $J_{o}$ [white dots on gray field fill and white diagonal lines on gray field fill for $\operatorname{VAM}(\mathrm{G})$ and $\operatorname{VAM}(\mathrm{H})$, respectively], are much reduced compared to the initial $J_{o}$ values, because the vector wind analyses are in much better agreement with the observations than the backgrounds. In the OSSE context, it is possible to calculate the vector RMS differences for background minus the truth $(B-T)$ and the analysis minus the truth $(A-T)$, and these are also shown in Fig. 4b. RMS vector difference is computed for 10553 grid points from the HNR1 27-km resolution domain ("truth") that fall within the region of the VAM analysis region at each of the 12 analysis times. During the tropical cyclone genesis period (i.e., before 0000 UTC 3 August), the RMS vector differences of the $\operatorname{VAM}(\mathrm{H})$ backgrounds and analyses compared to truth are larger than the RMS vector differences of the $\operatorname{VAM}(\mathrm{G})$ backgrounds and analyses compared to truth by about $0.5 \mathrm{~m} \mathrm{~s}^{-1}$. This is because the tropical storm is more developed in the HWRF backgrounds than the comparatively weak circulations in the GFS backgrounds, and both are displaced to the southwest of the HNR1 location. Therefore, position errors in the more developed HWRF backgrounds are penalized more than the weaker storm circulations in the GFS backgrounds. During rapid intensification (RI), however, 1200 UTC 3 August0000 UTC 5 August, the position of the storm in the HWRF backgrounds is corrected, while the GFS position remains too far west and south. GFS background vector wind differences, $B-T \operatorname{VAM}(\mathrm{G})$, during this period are about $0.63 \mathrm{~m} \mathrm{~s}^{-1}$ larger than $B-T \mathrm{VAM}(\mathrm{H})$ differences as a result of the displaced position of the storm in the GFS backgrounds. Also, the GFS storm position errors are large enough that $B-T \operatorname{VAM}(\mathrm{G})$ vector wind differences actually increase in $\operatorname{VAM}(\mathrm{G})$ analyses by about $0.35 \mathrm{~m} \mathrm{~s}^{-1}$, whereas $\operatorname{VAM}(\mathrm{H})$ analyses reduce the vector wind difference by about $0.56 \mathrm{~m} \mathrm{~s}^{-1}$. This illustrates the importance of storm position errors in the background wind fields used for vector wind analysis.

The average initial and final observation departures, $J_{o}$, are measures of the quality of the VAM backgrounds and analyses, respectively. In Table 1 the initial or final observation departure terms, $J_{o}$, are combined in weighted sums over all analysis cycles. These provide an overall assessment of the quality of the backgrounds and
TABLE 1. Prior and posterior VAM innovation statistics for GFS and HWRF backgrounds.

\begin{tabular}{ccc}
\hline $\begin{array}{c}\text { Overall statistics } \\
\left(\mathrm{m} \mathrm{s}^{-1}\right)\end{array}$ & $\begin{array}{c}\text { GFS } \\
\text { backgrounds }\end{array}$ & $\begin{array}{c}\text { HWRF } \\
\text { backgrounds }\end{array}$ \\
\hline RMS $o-b$ & 2.57 & 1.98 \\
RMS $o-a$ & 0.70 & 0.62 \\
\hline
\end{tabular}

analyses. Notice that the mean departure of the GFS backgrounds $(o-b)$ is $0.59 \mathrm{~m} \mathrm{~s}^{-1}$ larger than the HWRF backgrounds, indicating the higher quality of the HWRF backgrounds. Also, notice that the fit of the CYGNSS observations to the VAM analyses, $(o-a)$, are comparable with RMS differences of 0.62 and $0.70 \mathrm{~m} \mathrm{~s}^{-1}$ for analyses from GFS and HWRF backgrounds, respectively. This represents the misfit of observations to the analysis and is one measure of observation error.

As for the derived VAM-CYGNSS winds, it is useful to compare these to the original simulated CYGNSS wind speeds, since the derived vector observations will take the place of the original scalar observations. Over the 4-day period of this study $(N=129122)$, the mean $\mathrm{VAM}(\mathrm{G})$ wind speed is $0.070 \mathrm{~m} \mathrm{~s}^{-1}$ smaller than the mean simulated CYGNSS wind speed, and the mean $\operatorname{VAM}(\mathrm{H})$ wind speed is about $0.038 \mathrm{~m} \mathrm{~s}^{-1}$ smaller. These small differences show that the VAM-CYGNSS wind speeds are not biased compared to the simulated CYGNSS wind speeds. Figure 5 presents a comparison of the distributions of $\operatorname{VAM}(\mathrm{G})$ minus CYGNSS and VAM $(\mathrm{H})$ minus CYGNSS wind speed differences. Because the VAM acts as a spatial smoothing filter, the CYGNSS wind speeds are not recovered exactly. Also notice that the distribution of $\operatorname{VAM}(\mathrm{G})$ differences is skewed more negatively compared to the distribution of $\operatorname{VAM}(\mathrm{H})$ differences. This is another indication of the improved quality of the HWRF backgrounds compared to the GFS backgrounds. Finally, notice that the $\operatorname{VAM}(\mathrm{H})$ differences have two large negative outliers $\left(<-15 \mathrm{~m} \mathrm{~s}^{-1}\right)$. Because the $\operatorname{VAM}(\mathrm{H})$ winds are based on a higher-quality background, there are locations where high wind speed, simulated CYGNSS winds sampled near or in the eyewall of the HNR1 hurricane, happen to fall inside the eye of the hurricane in the HWRF background, resulting in large negative VAMCYGNSS wind speed departures. This is a side effect of combining CYGNSS observations in or near the eyewall with a high-fidelity source of information (i.e., HWRF background). Even small displacements between the center of circulation at an observation time and the center of circulation in a short-term forecast (e.g., HWRF or GFS 6-h forecasts in this study) can occasionally result in very large wind speed differences as seen in Fig. 5. This is an issue that all data assimilation 


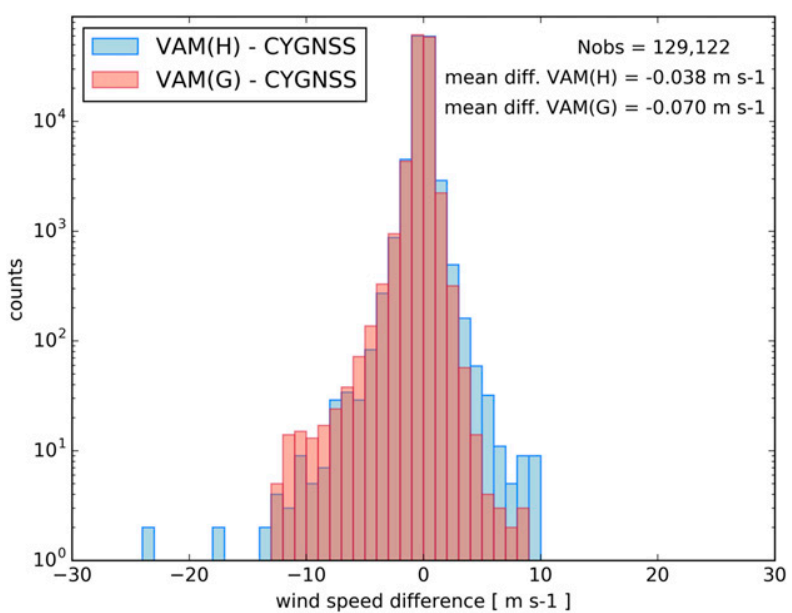

FIG. 5. Histograms of wind speed differences between derived $\operatorname{VAM}(\mathrm{G})$ and $\operatorname{VAM}(\mathrm{H})$ vector winds from simulated CYGNSS scalar wind speed for the 4-day experiment period.

systems face when using high-resolution, high-fidelity observations in or near the eyewall of tropical cyclones. Such mismatches are generally identified by various quality control checks that prevent such observations from upsetting or unbalancing the circulation in the analysis, if there is not a physically consistent approach to using them.

\section{OSSE evaluation}

Regional OSSEs using a version of the HWRF were conducted that assimilate CYGNSS wind speeds (CYG $\mathrm{SPD})$ and $\operatorname{VAM}(\mathrm{H})$ wind vectors (VAM VEC). The baseline or "control" experiment for these CYGNSS OSSEs assimilates observations simulated from the JONRs that are typically assimilated in NCEP operations (i.e., surface, including scatterometer, upper air, satellite, and atmospheric motion vector observations). The lateral boundary and initial conditions for the CYGNSS OSSEs come from the same GFS global control OSSE referenced in section 4. Therefore, in this OSSE the global JONR and the regional HNR1 are selfconsistent global and regional views, respectively, of the same truth that also drive the regional OSSEs. Note that CYGNSS winds are simulated from HNR1, but other observations are simulated from JONR. This is acceptable even though the TC in HNR1 is much more intense than in JONR because in this case there are essentially no control observations in the area close to the TC. A regional OSSE with $\operatorname{VAM}(\mathrm{G})$ vector winds was also conducted. But because of the position error in the GFS global control OSSE 6-h forecast fields (i.e., VAM backgrounds), assimilation of these vector winds produces results worse than the control and are not shown here. McNoldy et al. (2017) showed results for CYGNSS wind speeds with realistic errors and for perfect wind vectors sampled at the same specular points. Additional CYGNSS OSSEs conducted by the authors will be presented in a future separate journal article. The intent here is to show a limited set of the results that relate to the impact of the assimilation of scalar versus vector winds. The OSSE system will be described briefly here.

The OSSE system for these CYGNSS experiments uses a version of the HWRF (based on 2014 operations) that has an outer domain with 9-km grid spacing and a storm-following inner nest with 3-km grid spacing. GSI is the data assimilation component of the system, and this HWRF implementation uses no vortex relocation. Note that this is not a hybrid system and thus the background error covariances are static. The system is cycled every $3 \mathrm{~h}$ throughout the 4-day period of the simulated CYGNSS observations.

Figure 6 shows the average errors for a hurricane track (Fig. 6c) and two measures of intensity, maximum wind speed (Fig. 6d), and minimum sea level pressure (MSLP; Figs. $6 \mathrm{a}, \mathrm{b})$, as a function of forecast hour, every $6 \mathrm{~h}$, to $96 \mathrm{~h}$. The error at each 6-h forecast interval is an average of 12 forecasts. Figures $6 \mathrm{a}$ and $6 \mathrm{~b}$ show that the MSLP errors are reduced with respect to control (black) for both the CYG SPD and VAM VEC results, respectively. The $80 \%$ confidence interval is plotted around each line to indicate the significance of the differences. Notice that the VAM VEC MSLP errors are significantly reduced during the forecast hours $24-42$, whereas the improvement in the CYG SPD experiment is not as large. Figures $6 \mathrm{c}$ and $6 \mathrm{~d}$ show that track and maximum wind speed errors are not reduced as significantly as MSLP through the assimilation of CYGNSS wind information. The improvement of intensity (i.e., maximum wind and minimum central pressure) is larger and more consistent over all forecast times than the reduction of track error, with VAM VEC giving superior results out to $36 \mathrm{~h}$ for intensity.

As a way of investigating the physical effects on hurricane structure resulting from the cycling assimilation of CYGNSS scalar winds versus vector winds, Fig. 7 shows the HNR1, background, analysis, and GSI increments of 10-m winds valid on 1500 UTC 3 August from the CYG SPD and VAM VEC experiments.

Because the starting point for the CYGNSS OSSEs is the GFS global control OSSE fields, the significant displacement error noted in the VAM background fields (Fig. 3a) affects these OSSEs too. Therefore, in all experiments (control, CYG SPD, and VAM VEC) it takes $48 \mathrm{~h}$ of cycling DA to relocate the center of circulation closer to the HNR1 position (not shown). As noted earlier, the GFS position error is to the south and 

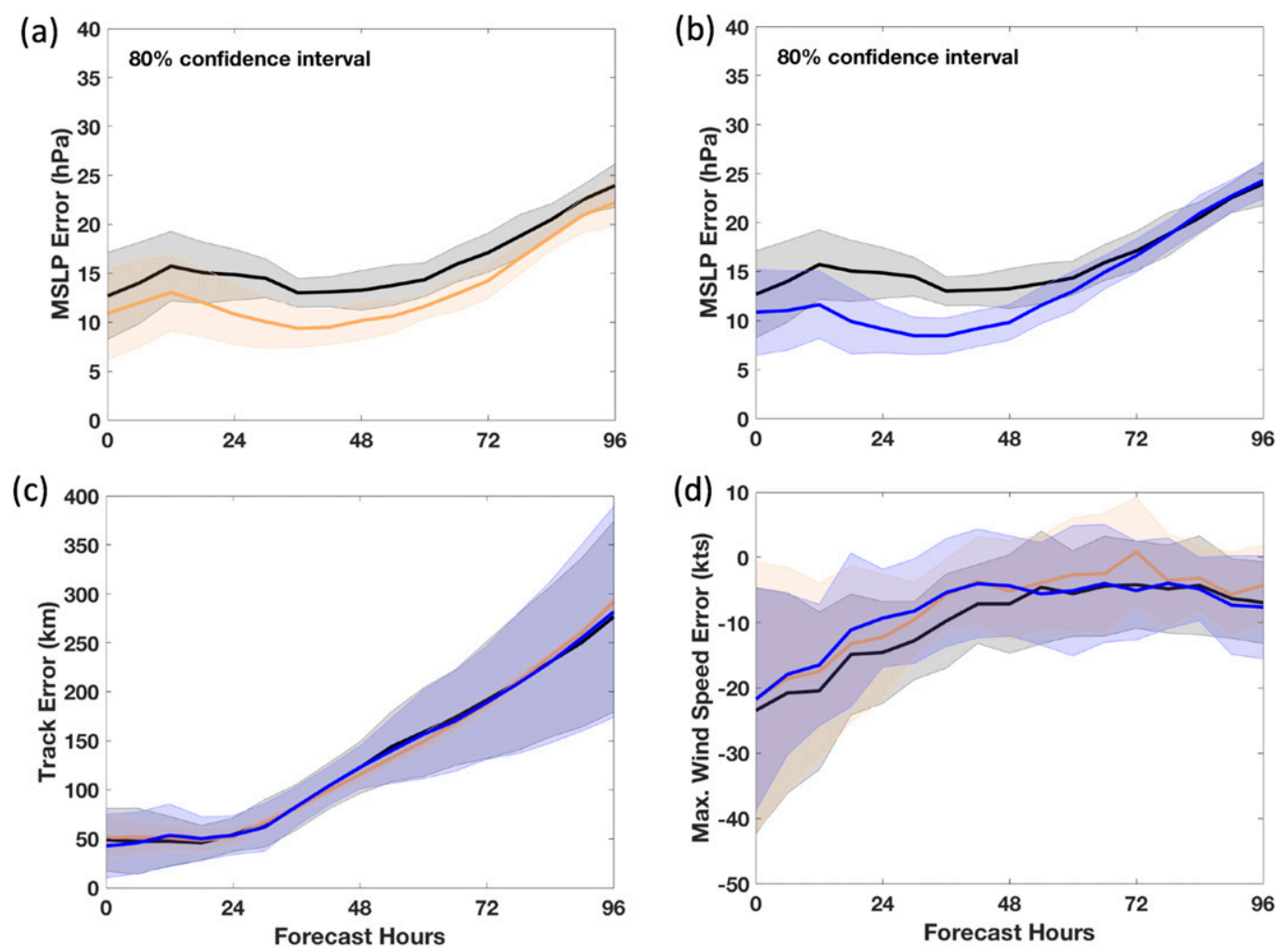

FIG. 6. Average forecast difference with respect to the nature run of (a),(b) central pressure (hPa) for control (black), CYG SPD (orange), and VAM VEC (blue) OSSEs, as a function of forecast time (h). The $80 \%$ confidence interval is plotted around each curve. (c) Hurricane track difference $(\mathrm{km})$, and (d) maximum wind difference $\left(\mathrm{m} \mathrm{s}^{-1}\right)$ with plus/minus the standard deviation plotted around each curve. Color convention is the same as in (a) and (b). Note: $N=12$ (5 days) forecasts.

significantly west of the nature run position. This is an indication that the storm moves westward too quickly and not far enough to the north in the GFS global control OSSE.

By 1500 UTC 3 August, the 3-h forecast background wind fields (Figs. 7c,d) benefit directly from the CYGNSS observations depicted in Figs. 1-3 valid at 1200 UTC and have relocated the circulation centers northward, correcting the initial southern displacement error. But circulation centers in both the CYG SPD and VAM VEC experiments are still too far to the west (position errors are 34 and $27 \mathrm{~km}$, respectively). The GSI analyses using all simulated conventional data and CYGNSS winds are shown in Figs. 7e and 7f. While the overall wind field size and structure in the backgrounds are similar, the GSI analyses using scalar and derived vector CYGNSS winds are quite different. Wind speed dipoles in the GSI analysis increments (Figs. 7g,h) show that the center is relocated in both analyses but in different directions. The CYG SPD center of circulation is moved toward the southwest, farther from the HNR1 position (position error is $39 \mathrm{~km}$ ), while the center of circulation in the VAM VEC analysis is moved to the east, closer to the HNR1 position (position error is $22 \mathrm{~km}$ ). Also, the structure of the wind field in the VAM VEC analysis is much closer to the HNR1 wind field than the CYG SPD analysis, because the scalar CYGNSS winds in this case produce large, unrealistic asymmetries in the analyzed wind field. In the figures, considering the wave 1 wind speed maximum, note that Fig. 7c is closest to Fig. 7a, and that Fig. $7 \mathrm{f}$ is second best. Thus, in this case the analysis of CYG SPD concentrates the wind speed maximum too much to the northern quadrant only, whereas the analysis of VAM VEC repositions the wind speed maximum properly, but it is still too weak. The introduction of unrealistic asymmetries by CYG SPD may require a recovery time for the storm to rebalance during the following forecast and DA cycles, similar to spinup/spindown issues noted immediately after assimilation in many hurricane DA systems. In contrast in the VAM VEC experiment, the analyses have a more symmetric overall TC structure, which may be partially responsible for the more realistic 
(a)

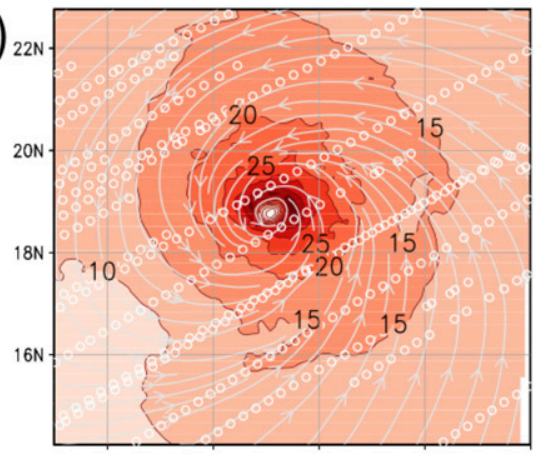

(c)

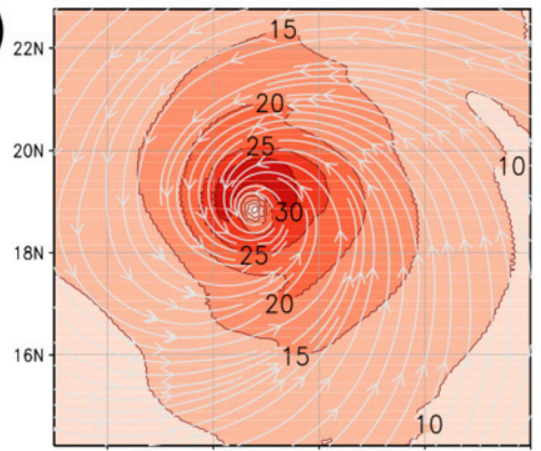

(e)

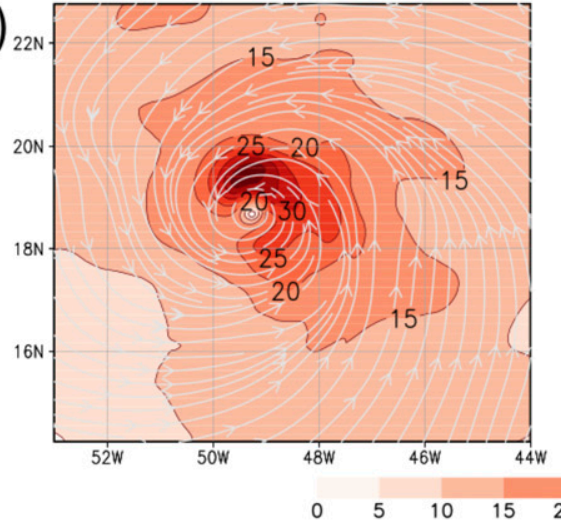

(b)

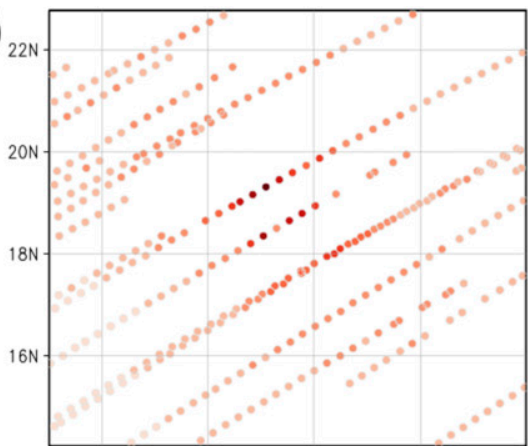

(d)

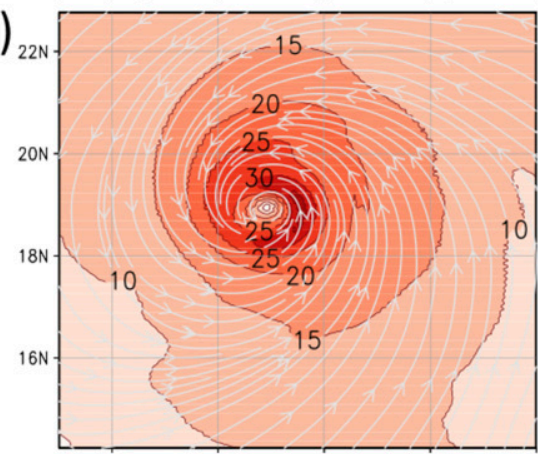

(f)

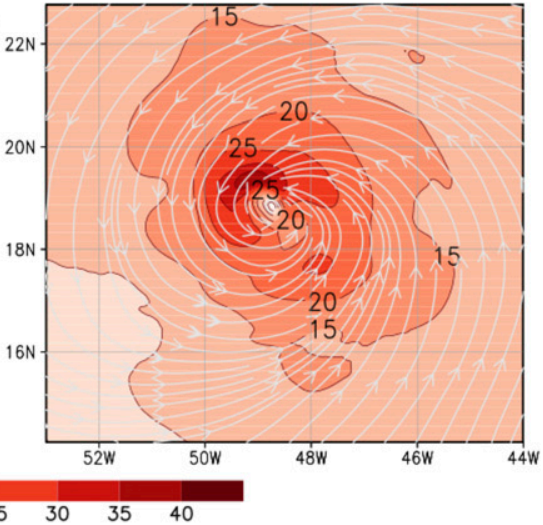

(g)

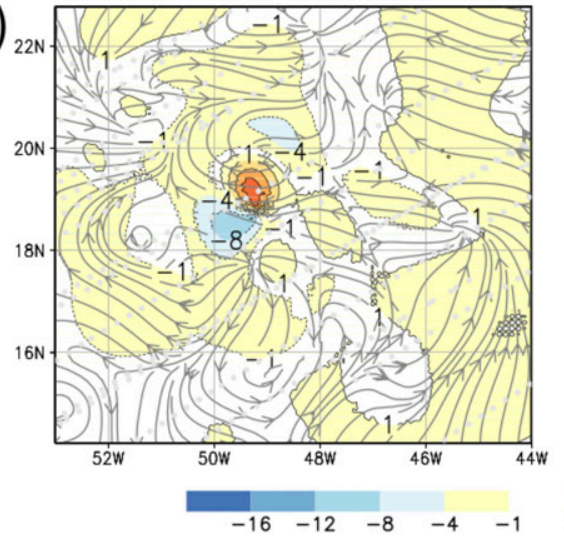

(h)

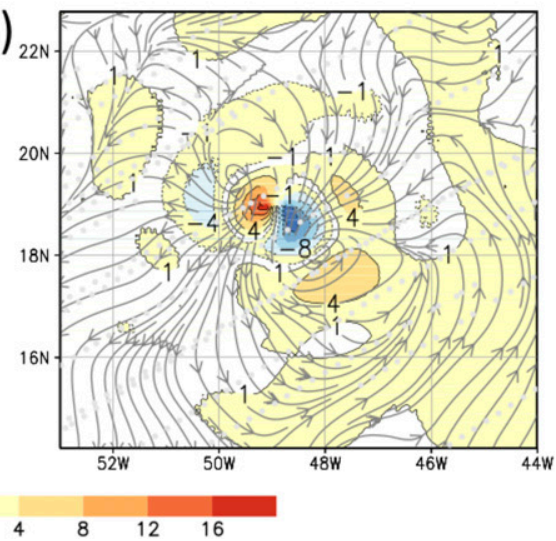

FIG. 7. Nature run (HNR1) winds and regional OSSE data assimilation results, valid at 1500 UTC 3 Aug 2005. (a) HNR1 10-m wind winds and (b) simulated CYGNSS winds in the \pm 1.5 -h window around 1500 UTC. (c),(d) HWRF 3-h forecast backgrounds; (e),(f) GSI analyses; and (g),(h) GSI analysis increments for (left) CYG SPD and (right) VAM VEC experiments. Every fifth CYGNSS data location is plotted with small gray circles in $(\mathrm{g})$ and $(\mathrm{h})$. 
intensification, especially during the first $48 \mathrm{~h}$ of the forecasts (cf. Fig. 6).

\section{Summary and conclusions}

Given the December 2016 launch of the CYGNSS observing system, new observations of ocean surface winds became available during 2017. For the first time, regular monitoring of wind speed within tropical cyclones (TCs) worldwide is available. The value of these observations for TC analysis may be increased if directional information is added. In this prelaunch study, simulated CYGNSS winds with added vector information were generated to assess the feasibility of such a process and the potential value of assimilating such observations. The prior study of McNoldy et al. (2017) examines bounding OSSEs using perfect CYGNSS vector observations, whereas this paper uses CYGNSS wind vectors derived from a variational analysis with realistic observation errors. This paper provides the background, method, and examples of deriving VAM-CYGNSS vector winds from the variational analysis of CYGNSS wind speeds with an appropriate prior or background wind field.

Observations from the CYGNSS constellation of microsatellites were simulated using a high-resolution nature run (HNR1; Nolan et al. 2013) of an Atlantic hurricane for a 4-day period. Then, a two-dimensional VAM for near-surface vector winds is applied every $6 \mathrm{~h}$ through the 4-day period to blend simulated CYGNSS wind speeds with an a priori background vector wind field at each analysis time to determine a set of geophysically self-consistent wind vectors at CYGNSS data locations. Two sources of background vector wind fields are used: low-resolution 6-h forecasts from a GFS model control OSSE and high-resolution 6-h forecasts from a related HWRF control OSSE. The resulting VAM analyses and CYGNSS winds with added vector information [VAM(H)] are compared and contrasted with the same results but derived using GFS control OSSE background wind fields $[\operatorname{VAM}(\mathrm{G})]$. The $\operatorname{VAM}(\mathrm{G})$ results were completed first as an early demonstration of VAM-CYGNSS wind vector data, while the $\operatorname{VAM}(\mathrm{H})$ results were produced later as a more refined approach. Practically, $\operatorname{VAM}(\mathrm{H})$ results are an "offline" test of generating VAM-CYGNSS winds. A future goal of this research is to test the "inline" generation and assimilation of VAM-CYGNSS winds during the CYGNSS mission within an HWRF nearoperational DA system for impact evaluation. Finally, a limited OSSE highlights the impacts of assimilating VAM-CYGNSS vector winds in comparison to CYGNSS scalar winds.
The results of the VAM analyses show that the VAMCYGNSS vector winds are sensitive to the choice of background. Given the large displacement error in the center of circulation in the GFS background wind fields, the VAM analysis wind speeds and directions using GFS backgrounds are significantly flawed, especially early in the 4-day period. The wind features in the GFS backgrounds are often misplaced with respect to the wind speed maxima in the simulated CYGNSS winds. This produces asymmetric circulations in the VAM analyses using GFS backgrounds that are reflected in the derived VAM-CYGNSS wind vectors. The VAM analyses using the HWRF background vector wind fields consistently produce VAM-CYGNSS wind vectors that match the HNR1 more closely. In this OSSE study, the location of the tropical cyclone circulation center was improved modestly by the use of VAM_CYGNSS vector winds compared to using simulated CYGNSS wind speed. Also, the intensity of the hurricane in the HWRF 6-h forecast fields is much closer to the HNR1 than the GFS backgrounds owing to the differing horizontal resolution and physical parameterizations between the GFS and HWRF models. The smoothing nature of the VAM reduces some of the very highest simulated CYGNSS wind speeds (i.e., $>35 \mathrm{~m} \mathrm{~s}^{-1}$ ), resulting in a small negative bias. But the overall distribution of the simulated CYGNSS wind speeds is generally reflected in the VAM-CYGNSS winds with added directional information.

The OSSE results indicate that CYGNSS winds, whether scalar or with added directional information, reduce the forecast error in hurricane intensity in 0-48-h forecasts compared to using no CYGNSS data (control). The improvement in forecast intensity is notably larger and more consistent with forecast hour than the reduction in track error. The assimilation of VAM-CYGNSS vector winds reduces the maximum wind speed error by $2-5 \mathrm{kt}$ (given a dynamic range of $\sim 5-25 \mathrm{kt}$ over $0-120$-h forecasts) and reduces the minimum central pressure error by $2-5 \mathrm{hPa}$ (given a dynamic range of $\sim 10-35 \mathrm{hPa}$ over $0-120$-h forecasts). From an examination of the analyzed surface wind field structures during the 4-day period of cycling data assimilation every $3 \mathrm{~h}$, CYGNSS scalar winds produce unwanted asymmetries as a result of incomplete sampling and the limitations of the GSI DA system more often than the assimilation of VAMCYGNSS data. The assimilation of VAM-CYGNSS vector winds seems to constrain the analysis of the surface wind field more effectively than wind speeds alone, leaving fewer opportunities for the introduction of wind/pressure imbalances and asymmetries in the analysis. 
The results of this study have limited applicability for a number of reasons. A single case study of one hurricane is examined that naturally biases the impacts seen toward this type of hurricane. Also, the static background error covariances used in this study would be improved with ensemble or hybrid DA. Finally, this study is based on simulated data for both observations and the nature run, which may differ from the real atmosphere and real CYGNSS observations in ways that have not been simulated. In reality, while satellite imagery is sufficient to indicate the general features of the wind direction field near a TC center, caution must be applied when using the VAM wind vectors in cases where no other observations are available for validation. Nevertheless, the indications are clear that CYGNSS data help DA systems produce better analysis of hurricane wind fields and 1-2-day intensity forecasts, particularly when assimilating VAM-CYGNSS vector winds. CYGNSS brings new eyes to monitor a difficult-toobserve and dangerous phenomenon in the global tropical oceans. During the 2017 hurricane season, dropwindsondes released during underflights of CYGNSS have allowed for calibration of CYGNSS algorithms and validation of VAM results. Observing system experiments (OSEs) with real CYGNSS data and HWRF during the 2017 hurricane season are shedding more light on the impact of this new and innovative observing system on a wider variety of cases.

Acknowledgments. This study was supported by NOAA directly and through the Cooperative Agreement NA15OAR4320064 for the Cooperative Institute for Marine and Atmospheric Studies (CIMAS). We thank Christopher Ruf at the University of Michigan and the CYGNSS Science Team for the simulated CYGNSS datasets, the NOAA Office of Weather and Air Quality for funding the development of the regional OSSE framework, the NOAA Hurricane Forecast Improvement Project for computing resources, the Developmental Testbed Center for the GSI and HWRF code and support, Sean Casey at CIMAS/AOML for providing the GFS control data, and David Nolan at the University of Miami for providing the WRF nature run dataset.

\section{REFERENCES}

Atlas, R., R. N. Hoffman, S. C. Bloom, J. C. Jusem, and J. Ardizzone, 1996: A multiyear global surface wind velocity data set using SSM/I wind observations. Bull. Amer. Meteor. Soc., 77, 869-882, https://doi.org/10.1175/1520-0477(1996) 077<0869:AMGSWV>2.0.CO;2.

,-- J J. Ardizzone, S. M. Leidner, J. C. Jusem, D. K. Smith, and D. Gombos, 2011: A cross-calibrated, multiplatform ocean surface wind velocity product for meteorological and oceanographic applications. Bull. Amer. Meteor. Soc., 92, 157-174, https://doi.org/10.1175/2010BAMS2946.1.

Casey, S. P. F., R. Atlas, S. A. Boukabara, R. N. Hoffman, K. Ide, M. Masutani, I. Moradi, and J. S. Woollen, 2016: Geostationary hyperspectral infrared constellation: Global observing system simulation experiments for five Geo-HSS instruments. 20th Conf. on Integrated Observing and Assimilation Systems for the Atmosphere, Oceans, and Land Surface (IOAS$A O L S)$, New Orleans, LA, Amer. Meteor. Soc., J7.4, https:// ams.confex.com/ams/96Annual/webprogram/Paper283540. html.

Clarizia, M. P., and V. Zavorotny, 2015: CYGNSS Algorithm Theoretical Basis Document Level 2 wind speed retrieval. Revision 2, Change 2, University of Michigan Doc. 148-0138, $95 \mathrm{pp}$.

Gall, R., J. Franklin, F. Marks, E. N. Rappaport, and F. Toepfer, 2013: The hurricane Forecast Improvement Project. Bull. Amer. Meteor. Soc., 94, 329-343, https://doi.org/10.1175/ BAMS-D-12-00071.1.

Gleason, S. T., S. Hodgart, S. Yiping, C. Gommenginger, S. Mackin, M. Adjrad, and M. Unwin, 2005: Detection and processing of bistatically reflected GPS signals from low Earth orbit for the purpose of ocean remote sensing. IEEE Trans. Geosci. Remote Sens., 43, 1229-1241, https://doi.org/10.1109/ TGRS.2005.845643.

Hoffman, R. N., 1982: SASS wind ambiguity removal by direct minimization. Mon. Wea. Rev., 110, 434-445, https://doi.org/ 10.1175/1520-0493(1982)110<0434:SWARBD>2.0.CO;2.

, 1984: SASS wind ambiguity removal by direct minimization. Part II: Use of smoothness and dynamical constraints. Mon. Wea. Rev., 112, 1829-1852, https://doi.org/10.1175/ 1520-0493(1984)112<1829:SWARBD>2.0.CO;2.

— S. M. Leidner, J. M. Henderson, R. Atlas, J. V. Ardizzone, and S. C. Bloom, 2003: A two-dimensional variational analysis method for NSCAT ambiguity removal: Methodology, sensitivity, and tuning. J. Atmos. Oceanic Technol., 20, 585-605, https://doi.org/10.1175/1520-0426(2003)20<585: ATDVAM $>2.0 . \mathrm{CO} ; 2$.

Laprise, R., 1992: The resolution of global spectral models. Bull. Amer. Meteor. Soc., 73, 1453-1454, https://doi.org/10.1175/ 1520-0477-73.9.1453.

Masutani, M., and Coauthors, 2009: International collaborative joint OSSEs-Toward reliable and timely assessment of future observing systems. Anthony J. Hollingworth Symp., Phoenix, AZ, Amer. Meteor. Soc., P1.2, https://ams.confex. com/ams/89annual/techprogram/paper_149641.htm.

McNoldy, B., B. Annane, S. Majumdar, J. Delgado, L. Bucci, and R. Atlas, 2017: Impact of assimilating CYGNSS data on tropical cyclone analyses and forecasts in a regional OSSE framework. Mar. Technol. Soc. J., 51 (1), 7-15, https://doi.org/ 10.4031/MTSJ.51.1.1.

NOAA, 2015: Global Forecast System: Running global model parallel experiments. Version 6.0, NOAA/NWS/NCEP/EMC/ Global Climate and Weather Modeling Branch, 41 pp., http:// www.emc.ncep.noaa.gov/GFS/docs/running_global_model_ parallel_experiments_v6.0.pdf.]

Nolan, D. S., R. Atlas, K. T. Bhatia, and L. R. Bucci, 2013: Development and validation of a hurricane nature run using the joint OSSE nature run and the WRF model. J. Adv. Model. Earth Syst., 5, 382-405, https://doi.org/10.1002/jame.20031.

NWS, 2014: Corrected: Global Forecast Systems (GFS) update: Effective January 14, 2015. NWS Tech. Implementation 
Notice TIN14-46, http://www.nws.noaa.gov/os/notification/ tin14-46gfs_cca.htm.

O'Brien, A., 2014: CYGNSS end-to-end simulator technical memo. University of Michigan Doc. 148-0123, 23 pp., http:// clasp-research.engin.umich.edu/missions/cygnss/reference/ 148-0123_CYGNSS_E2ES_EM.pdf.

Reale, O., J. Terry, M. Masutani, E. Andersson, L. P. Riishojgaard, and J. C. Jusem, 2007: Preliminary evaluation of the European Centre for Medium-Range Weather Forecasts' (ECMWF) nature run over the tropical Atlantic and African monsoon region. Geophys. Res. Lett., 34, L22810, https://doi.org/ 10.1029/2007GL031640.

Ruf, C. S., and Coauthors, 2016: New ocean winds satellite mission to probe hurricanes and tropical convection. Bull. Amer. Meteor. Soc., 97, 385-395, https://doi.org/10.1175/BAMS-D-14-00218.1.

Stauffer, D. R., and N. L. Seaman, 1990: Use of four-dimensional data assimilation in a limited-area mesoscale model. Part I: Experiments with synoptic-scale data. Mon. Wea. Rev., 118, 1250-1277, https://doi.org/10.1175/1520-0493(1990)118<1250: UOFDDA $>2.0 . \mathrm{CO} ; 2$. 